(c) American Dairy Science Association, 2006.

\title{
Activity and Nature of Plasminogen Activators Associated with the Casein Micelle
}

\author{
B. Ismail, ${ }^{*}$ L. H. Choi, $†$ L. M. Were, $\ddagger$ and S. S. Nielsen*1 \\ ${ }^{*}$ Purdue University, Department of Food Science, 745 Agricultural Mall Drive, West Lafayette, IN 47907 \\ †General Mills, Inc., 9000 Plymouth Blvd. North, Minneapolis, MN 55427 \\ $\ddagger$ Chapman University, Department of Physical Sciences, 1 University Drive, Orange, CA 92866
}

\section{ABSTRACT}

In fresh milk, plasminogen, the zymogen form of plas$\min (\mathrm{PL})$, is the predominant form. Therefore, plasminogen activators (PA) can contribute significantly to PL activity in milk. Both tissue-type PA (tPA) and urokinase-type PA (uPA) exist in milk; however, contradictory findings have been reported for which type of PA is most closely associated with the casein micelles. Little is known about the factors that might lead to variations in the individual activities of the PA. The objective of this work was therefore to investigate possible factors that might affect the association of tPA and uPA with the casein micelle and their activities thereafter. Plasminogen activators were isolated from milk samples with different somatic cell counts following 2 different isolation protocols. Determination of uPA, tPA, and PL activities was carried out quantitatively following chromogenic assays using 2 different substrates, and qualitatively using specialized sodium dodecyl sulfatePAGE. Different isolation methods and conditions led to differences in UPA, tPA, and PL activities. Urokinase-type PA activity was significantly higher in PA fractions isolated from milk with high somatic cell counts than from milk with low somatic cell counts. Activity results indicated that in pasteurized milk uPA could dissociate from the somatic cells and bind to casein. Moreover, a high level of PL in isolated PA fractions contributed to significantly enhanced PA activities. Overall, results confirmed the association of both uPA and tPA with the casein micelle; however, their amounts, activities, and molecular weights varied based on the nature of the milk and methods of separation, with uPA being the PA with greater potential to affect plasminogen activation in milk.

Key words: plasmin system, plasminogen activator, somatic cell count, casein micelle

Received February 16, 2006

Accepted March 17, 2006.

${ }^{1}$ Corresponding author: nielsens@purdue.edu

\section{INTRODUCTION}

Proteolysis in milk is known to be caused by native proteases and proteases produced by psychrotrophic microorganisms (Fairbairn and Law, 1986; Grufferty and Fox, 1988). Proteolysis, caused by the principal native proteinase plasmin (PL; EC 3.4.21.7), has attracted great interest among researchers because of its complexity and versatile effects on quality. Plasmin activity is sometimes essential and desirable for flavor development and texture changes during the ripening of cheese, thus enhancing the product quality. Conversely, uncontrolled proteolysis can have a detrimental effect on the quality, such as poor curd formation (Srinivasan and Lucey, 2002), gelation of stored UHT milk (Kohlmann et al., 1991), and degradation of stored $\mathrm{CN}$ intended to be used as functional enhancers in food (Nielsen, 2002).

Plasmin is an alkaline serine proteinase, which hydrolyzes mostly $\alpha_{\mathrm{s} 1}-\mathrm{CN}, \alpha_{\mathrm{s} 2}$-CN, and $\beta$-CN (Grufferty and Fox, 1988; Bastian and Brown, 1996). Plasmin is part of a complex system, commonly referred to as the PL system, which includes its zymogen plasminogen (PG), PG activators (PA), PA inhibitors (PAI), and PL inhibitors (PI). Plasmin inhibitors and PAI are associated with milk serum (Precetti et al., 1997), whereas PL, PG, and PA are associated with CN micelles (Politis et al., 1992). The interactions among PG, PL, PA, PAI, and PI, which characterize the PL system, have been studied by several researchers, as elaborately discussed in review articles by Grufferty and Fox (1988) and Bastian and Brown (1996). Storage, heat treatment, and $\mathrm{pH}$ are among the most important factors affecting the PL system in milk and dairy products.

In fresh milk, PG is the predominant form, with a concentration 2 to 20 times that of PL (Richardson and Pearce, 1981; Bastian and Brown, 1996). Therefore, any potential activation of $\mathrm{PG}$ could contribute significantly to PL activity in milk. The conversion of PG into PL is mediated by at least 2 types of PA, tissue-type (tPA; EC 3.4.21.68) and urokinase-type (uPA; EC 3.4.21.73), which also are serine proteinases (Bastian and Brown, 1996). Both tPA and uPA convert bovine PG to PL by 
hydrolyzing the Arg557-Ile558 bond while the milk is in the mammary lumen prior to milking and during milk storage (Driessen and Van Der Waals, 1978; Schaar, 1985; Alichanidis et al., 1986). Compared with other components of the PL system in bovine milk, little work has been done on PA. Plasminogen activators are thought to be even more heat stable than PL and PG ( $\mathrm{Lu}$ and Nielsen, 1993); thus, they survive pasteurization when PAI do not (Richardson, 1983; Prado et al., 2006). Therefore, understanding PA in milk is essential because they could have a significant effect on PL activity, which in turn can cause either beneficial or detrimental proteolysis in dairy foods.

Little is known about the difference in activity between the 2 known types of PA (tPA and uPA). Researchers have found that tPA activity is significantly enhanced by fibrin (Rånby et al., 1982; Karlan et al., 1987), and that both tPA and UPA activities are stimulated by CN (Markus et al., 1993; Politis et al., 1995). Furthermore, Heegaard et al. (1994) observed that amiloride inhibits uPA activity but has no effect on tPA. It is commonly believed that PA are associated with $\mathrm{CN}$; however, conflicting results have been observed by several researchers regarding which PA is predominantly associated with the CN micelle (Lu and Nielsen, 1993; Heegaard et al., 1994; White et al., 1995). Lu and Nielsen (1993) identified 5 proteins with PA-like activities associated with the CN fraction. Heegaard et al. (1994) reported that tPA was 100 -fold more abundant than uPA in the CN fraction. White et al. (1995) found that $50 \%$ of PA activity associated with $\mathrm{CN}$ is attributed to tPA. Heegaard et al. (1994) and White et al. (1995) confirmed the absence of PA from the whey fraction. The association of uPA (Heegaard et al., 1994; White et al., 1995) and tPA (Zachos et al., 1992) with somatic cells has been observed. White et al. (1995) linked the association of tPA with somatic cells to the presence of CN remnants in the cell extracts, and thus concluded that tPA is the main PA associated with the CN micelle and that uPA is associated with the somatic cells. Obviously, tPA and uPA are both present in milk, and the discrepancy in results could be attributed to many factors. Urokinase-plasminogen activators can dissociate from the somatic cells and be picked up by $\mathrm{CN}$ and physically bind to it. Therefore, the SCC in milk, the time the somatic cells stay in milk, and the heat treatment of milk could be factors affecting the dissociation of uPA from the somatic cells. The presence of PL can lead to the conversion of single-chain uPA and tPA into 2-chain proteins with significantly enhanced activities (Ugwu et al., 1998); thus, the amount of PL in milk and in the isolated PA solution will be another source of variation affecting the results. Other factors leading to conflicting results could be differences in methods of
PA isolation from the $\mathrm{CN}$ micelle and the substrates used in the chromogenic assays. Therefore, the purpose of this study was to dissociate and isolate PA under various conditions and test activities using different substrates to better understand the activity and nature of PA associated with the $\mathrm{CN}$ micelle.

\section{MATERIALS AND METHODS}

\section{Source of Milk and Reagents}

Fresh raw milk was collected from 5 mid lactation, second-calving cows (Purdue University Dairy Research Farm) on several occasions over a 2-wk period. Samples of the collected milk were sent out for proximate analysis and SCC measurement (Universal Lab Services, Lansing, MI). Only milk samples with widely varied SCC were processed further for determination of PA. The 2 chosen milk samples were subjected to HTST pasteurization at $72^{\circ} \mathrm{C}$ for $15 \mathrm{~s}$ using a pilot-scale plate heat exchanger (FT 74; Armfield, Jackson, NJ).

D-Valyl-L-leucyl-L-lysine 4-nitroanilide dihydrochloride (S-2251, product \#V0882) and amiloride (product \#A7410) were purchased from Sigma Chemical Co. (St. Louis, MO). $H$-D-Norleucyl-hexahydrotyrosol-lysine- $p$ nitroanilide diacetate [Spectrozyme PL (SpecPL), product \#251L], bovine PG (product \#416), urokinase (product \#124), 2-chain tPA (product \#116), and cyanogen bromide fibrinogen digest (FIBGN; product \#459) were purchased from American Diagnostica (Greenwich, CT). Bovine PL (product \#602 370) was purchased from Roche Diagnostics (Indianapolis, IN). All reagents were diluted to appropriate concentrations in either deionized distilled water or 0.05 modified Tris buffer (MTB; $0.05 M$ Tris, $0.1 M$ NaCl, $0.01 \%$ Tween 80; $\mathrm{pH}$ 7.6) depending on the substrate protocol.

Casein-Hammerstein (CN-Hammerstein; product \#101289) was obtained from ICN Biomedicals, Inc. (Aurora, OH). Prestained broad-range SDS-PAGE standards (product \#161-0318), 40\% acrylamide-bis solution (2.6\% crosslinking), 10× Tris-Gly-SDS (product \#1610732), and criterion cassettes (product \#345-9981) were obtained from BioRad Laboratories, Inc. (Hercules, CA) for the specialized electrophoresis gels. A micro bicinchoninic acid protein assay kit (Micro BCA, product \#23225; Pierce Chemical Co., Rockford, IL) was used for protein determination following the manufacturer's instructions.

\section{Dissociation and Isolation of PA from the CN Micelle}

To address contradictory results advanced in previously reported work, and to gain a better understanding of the activity and nature of PA associated with the 
CN micelle, 2 milk samples with widely varied SCC were subjected to different PA isolation conditions and protocols. The PA isolation protocol and reagents used were adopted from the work of DeHarveng and Nielsen (1991) and White et al. (1995), in which each group of researchers provided justifications for their proposed procedures. Each pasteurized milk, having different SCC, was randomly divided, in triplicate, into 4 (600$\mathrm{mL}$ ) samples that were defatted by centrifuging (Avanti J25I Centrifuge; Beckman, Fullerton, CA) at 4,000 $\times g$ for $20 \mathrm{~min}$ at $4^{\circ} \mathrm{C}$ and randomly assigned to 1 of 4 treatments (PA isolation conditions and protocols). Somatic cells were retained in one of the defatted milk samples, and isolation of PA was carried out for that sample as outlined by DeHarveng and Nielsen (1991), without modifications, to produce a PA solution referred to as supernatant 2 (Sup2; Figure 1). Somatic cells were removed from the second defatted milk sample, and isolation of PA was carried out as outlined by DeHarveng and Nielsen (1991) without modifications. Somatic cells were removed from the third defatted milk sample, and isolation of PA was carried out as outlined by White et al. (1995), without modifications, to produce supernatant (White Sup) and CN (White CN) fractions (Figure 2). Somatic cells were removed from the fourth defatted milk sample, and isolation of PA was carried out as outlined by DeHarveng and Nielsen (1991) with one modification in the ultracentrifugation step, which was increased from 70,000 to $100,000 \times g$ to obtain the same CN pellet as the one obtained following the method used by White et al. (1995). All extractions were carried out in triplicate.

\section{Chromogenic Assays}

Chromogenic Coupled Assay to Measure uPA Activity. The coupled assay used to measure uPA activity was based on the method outlined by Lu and Nielsen (1993) with some modifications. To determine uPA activity, the sample was mixed with MTB, bovine PG, and the chromogenic substrate, either SpecPL or S2251. A blank that consisted of MTB, bovine PG, and substrate was prepared, as well as a control for every treatment that consisted of sample, MTB, and substrate. The volumes and concentrations of reagents used are listed in Table 1 . In triplicate, reaction mixtures were prepared to a total volume of $400 \mu \mathrm{L}$ in microcentrifuge tubes and were incubated for $2 \mathrm{~h}$ in a water bath set at $37^{\circ} \mathrm{C}$. After incubation, tubes were microcentrifuged at $15,600 \times g$ for $5 \mathrm{~min}$ and a $100-\mu \mathrm{L}$ sample was pipetted into 3 wells of a 96 -well microtiter plate. Absorbance was measured at 405 and $490 \mathrm{~nm}$ (subtracted to correct for added absorbance caused by turbidity) using a Vmax kinetic microtiter plate reader
(Molecular Devices, Sunnyvale, CA). Based on absorbance values, units of activity of uPA were calculated per $1 \mathrm{mg}$ of protein in the sample. One unit was defined as the change of $0.1 \mathrm{~nm}$ in absorbance. Therefore, units of activity of uPA were calculated as follows:

$$
\begin{aligned}
& \text { units of activity }=(\text { absorbance value } \\
& \times \text { dilution factor } / 0.1) / \mathrm{mg} \text { of protein }
\end{aligned}
$$

\section{Chromogenic Coupled Assay to Measure tPA Ac-} tivity. The coupled assay used to measure tPA activity also was based on the method outlined by Lu and Nielsen (1993) with some modifications. Amiloride, to inhibit UPA activity, and FIBGN, to stimulate tPA activity, were used to differentiate tPA activity from uPA activity. The amiloride and FIBGN concentrations used ensured inhibition of uPA and enhancement of tPA, respectively. It was previously proven that amiloride inhibits uPA but not tPA, and that FIBGN is required for the detection of tPA activity chromogenically (Rånby et al., 1982; Karlan et al., 1987; Heegaard et al., 1994; White et al., 1995). Therefore, to determine tPA activity, the sample was mixed with MTB, bovine PG, amiloride, FIBGN, and the chromogenic substrate, either SpecPL or S-2251. A blank was prepared that consisted of MTB, bovine PG, amiloride, FIBGN, and substrate, and a control was prepared for every treatment that consisted of sample, MTB, amiloride, FIBGN, and substrate. The volumes and concentrations of reagents used are listed in Table 2. Thereafter, determination of tPA activity was completed as outlined in the previous section.

Chromogenic PL and PG Activity Assays. Plasmin and $P G$ activities of the isolated fractions were measured, in triplicate, following the chromogenic assays outlined by Fajardo-Lira and Nielsen (1998), with minor modifications in the volumes and concentrations used. For PL determination, in a microcentrifuge tube, sample (100 $\mu \mathrm{L})$ was added to $300 \mu \mathrm{L}$ of $1.6 \mathrm{mM}$ SpecPL and allowed to react for $1 \mathrm{~h}$ at $37^{\circ} \mathrm{C}$ in a water bath. For PG determination, in a microcentrifuge tube, sample $(100 \mu \mathrm{L})$ was added to $100 \mu \mathrm{L}$ of $3.2 \mathrm{mM}$ SpecPL, $100 \mu \mathrm{L}$ of human $\mathrm{uPA}(280 \mathrm{IU} / \mathrm{mL})$, and $100 \mu \mathrm{L}$ of MTB, and the reaction mixture was allowed to react for $1 \mathrm{~h}$ at $37^{\circ} \mathrm{C}$ in a water bath. Proper blank and control mixtures were prepared. Determination of PL and PG procedures continued as described in the previous sections. Units of activity also were calculated as described above.

\section{Specialized Gel Electrophoresis}

Discontinuous SDS-PAGE and CN-PG SDS-PAGE gels, each consisting of $15 \%$ acrylamide resolving gel 
Fresh milk (mid lactation, 2nd calving)
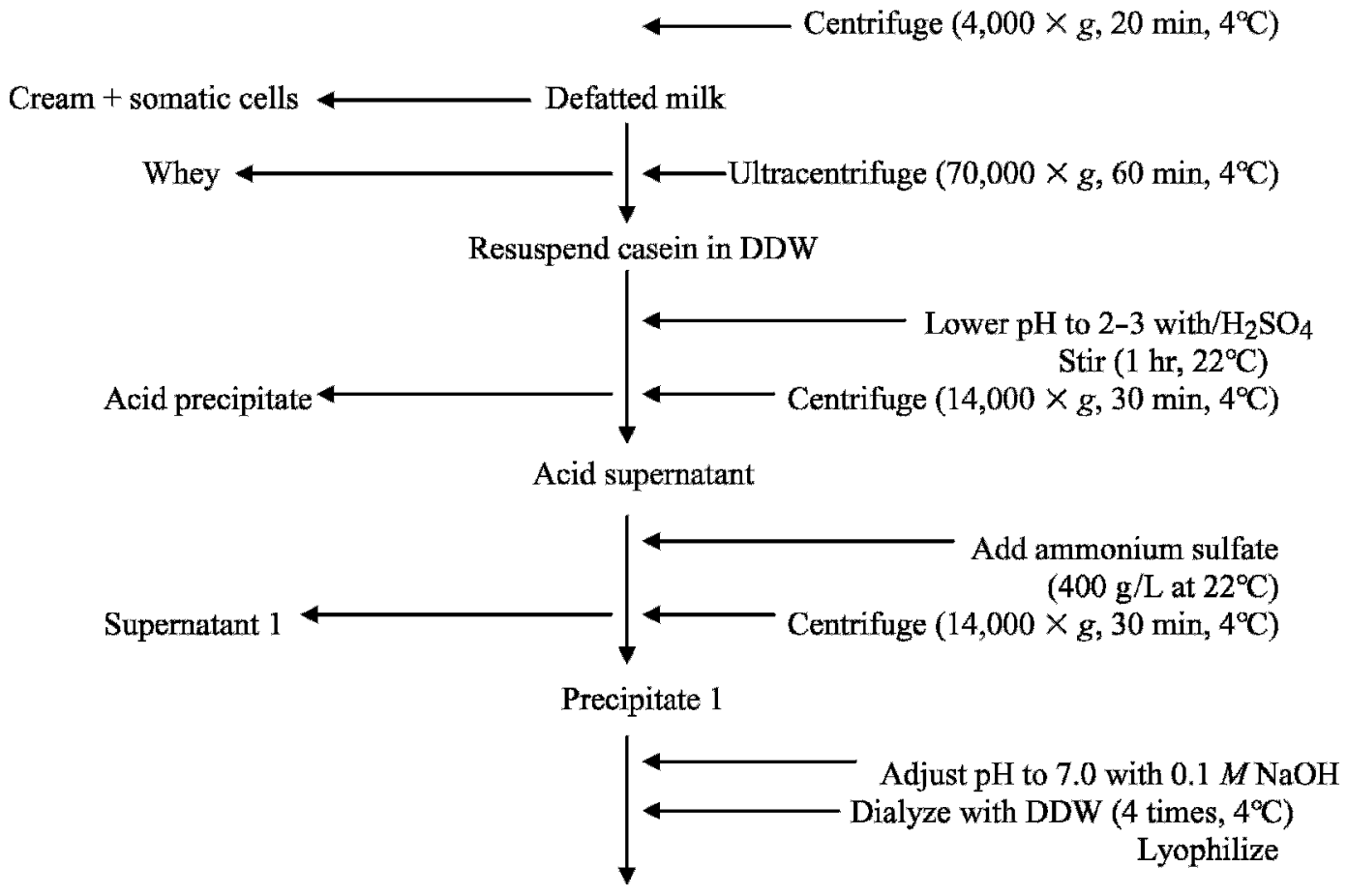

$2 \%(\mathrm{wt} / \mathrm{vol})$ solution of lyophilized material in $0.023 M$ phosphate buffer, $\mathrm{pH} 7.0$

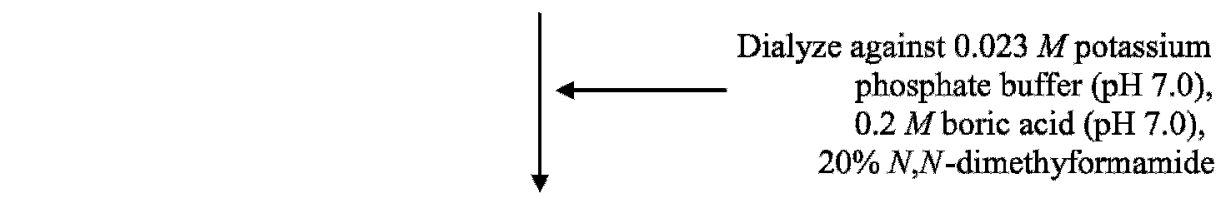

Add saturate ammonium sulfate solution., 1:1 ratio

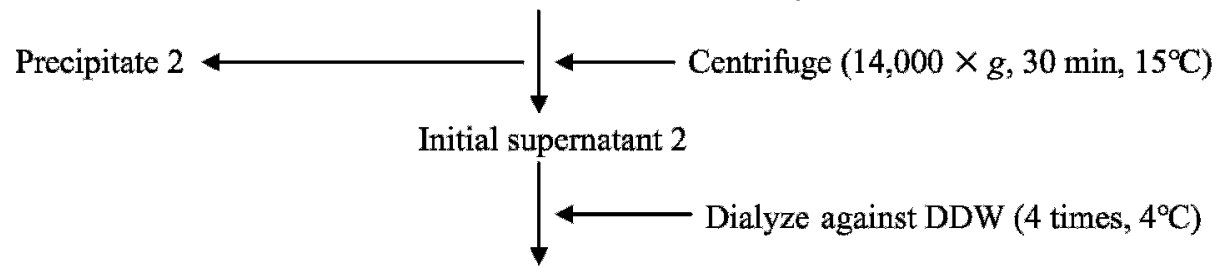

Final supernatant 2

Figure 1. Plasminogen activator isolated according to the method of DeHarveng and Nielsen (1991). DDW = deionized distilled water.

(15\% $\mathrm{T}$, and $2.6 \% \mathrm{C}$ ) and $4 \%$ acrylamide stacking gel, were hand-casted following the formula outlined in Table 3. The SDS-PAGE was carried out to observe and identify PA proteins, whereas the CN-PG SDS-PAGE was carried out to observe PG activation by PA as indicated by zones of clearance (caused by hydrolysis of embedded CN). The CN-PG SDS-PAGE gel was prerun for $1.5 \mathrm{~h}$ at $200 \mathrm{~V}$. For SDS-PAGE, standard solutions of $\beta$-CN, PL, PG, high molecular weight uPA (52 kDa), and 2-chain tPA (70 kDa) were prepared, with concen- trations of $0.25,0.114,0.25,0.07$, and $0.02 \mathrm{mg} / \mathrm{mL}$, respectively. For CN-PG SDS-PAGE, standard solutions of PL, high molecular weight uPA, and 2-chain tPA were prepared, with activities of $62.5 \mathrm{mU} / \mathrm{mL}, 3.1 \mathrm{IU} /$ $\mathrm{mL}$, and $170 \mathrm{IU} / \mathrm{mL}$, respectively. Standard solutions and samples of PA solutions isolated under different conditions were mixed 1:2 (vol/vol) with Laemmli buffer under nonreducing conditions and held at room temperature $\left(22^{\circ} \mathrm{C}\right)$ for $30 \mathrm{~min}$. The protein contents of isolated PA solutions were close in value $(0.2$ to $0.5 \mathrm{mg} / \mathrm{mL})$, 
Fresh milk (mid lactation, 2nd calving)

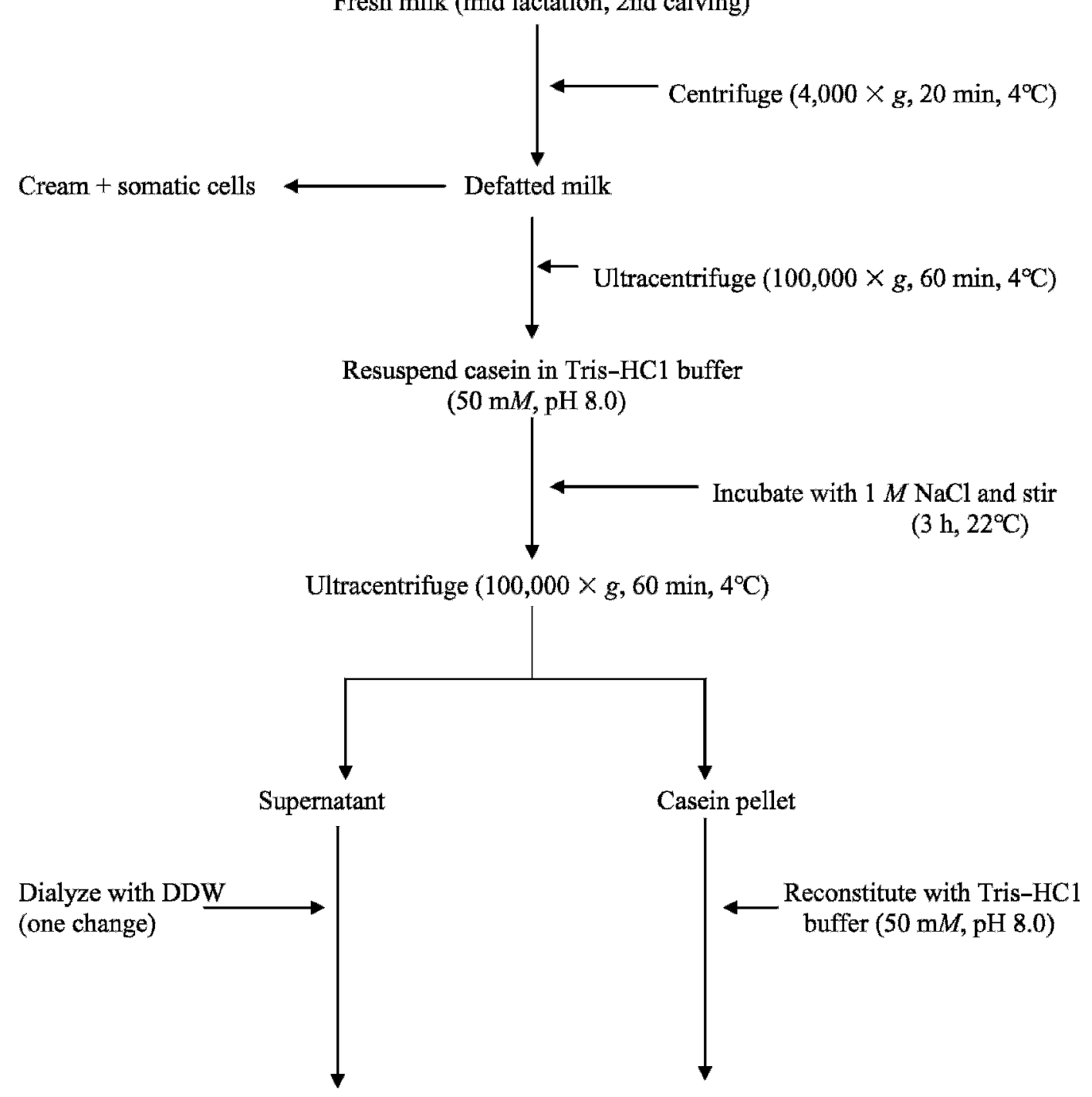

Store at $-20^{\circ} \mathrm{C}$ until used

Figure 2. Plasminogen activator isolated by the method of White et al. (1995). DDW = deionized distilled water.

Table 1. Volumes $(\mu \mathrm{L})$ and concentrations of reagents used for assay of urokinase-type plasminogen activator activity ${ }^{1}$

\begin{tabular}{|c|c|c|c|c|}
\hline $\begin{array}{l}\text { Reaction } \\
\text { mixture }\end{array}$ & Sample & $\begin{array}{l}\text { MTB, } \\
0.05 M \\
\text { pH } 7.5\end{array}$ & $\begin{array}{l}\text { PG, } \\
0.032 \mathrm{mg} / \mathrm{mL}\end{array}$ & $\begin{array}{l}\text { SpecPL } \\
\text { or S-2251, } \\
3.2 \mathrm{~m} M\end{array}$ \\
\hline Blank & 0 & 200 & 100 & 100 \\
\hline Control & 100 & 200 & 0 & 100 \\
\hline Sample & 100 & 100 & 100 & 100 \\
\hline
\end{tabular}

${ }^{1} \mathrm{MTB}=$ modified Tris buffer; PG = plasminogen; SpecPL = Spectrozyme PL ( $H$-D-norleucyl-hexahydrotyrosol-lysine- $p$-nitroanilide diacetate; American Diagnostica, Greenwich, CT); S-2251 = D-valyl-Lleucyl-L-lysine 4-nitroanilide dihydrochloride (Sigma Chemical Co., St. Louis, MO). except for the CN fraction, which was isolated as outlined by White et al. (1995) and which, on average, was $1.7 \mathrm{mg}$ protein $/ \mathrm{mL}$. Therefore, after mixing the samples with the Laemmli buffer, $20 \mu \mathrm{L}$ of each sample was loaded on the gel (SDS-PAGE gel or CN-PG SDS-PAGE gel), except for the White CN fraction, for which only $5 \mu \mathrm{L}$ of aliquot was loaded. An aliquot $(15 \mu \mathrm{L})$ of prestained broad-range molecular weight standards was loaded on both the SDS-PAGE and CN-PG SDSPAGE gels. Running conditions of both gels and the incubation protocol for the CN-PG SDS-PAGE gel, as well as the staining and destaining procedures, were performed as outlined by Fajardo-Lira et al. (2000), 
Table 2. Volumes $(\mu \mathrm{L})$ and concentrations of reagents used for assay of tissue-type plasminogen activator activity $^{1}$

\begin{tabular}{|c|c|c|c|c|c|c|}
\hline $\begin{array}{l}\text { Reaction } \\
\text { mixture }\end{array}$ & Sample & $\begin{array}{l}\text { FIBGN, } \\
0.27 \mathrm{mg} / \mathrm{mL}\end{array}$ & $\begin{array}{l}\text { MTB, } \\
0.05 M \\
\text { pH } 7.5\end{array}$ & $\begin{array}{l}\text { PG, } \\
0.032 \\
\mathrm{mg} / \mathrm{mL}\end{array}$ & $\begin{array}{l}\text { SpecPL } \\
\text { or S-2251, } \\
3.2 \mathrm{mM}\end{array}$ & $\begin{array}{l}\text { Amiloride, } \\
10 \mathrm{~m} M\end{array}$ \\
\hline Blank & 0 & 60 & 100 & 100 & 100 & 40 \\
\hline Control & 100 & 60 & 100 & 0 & 100 & 40 \\
\hline Sample & 100 & 60 & 0 & 100 & 100 & 40 \\
\hline
\end{tabular}

${ }^{1}$ FIBGN = cyanogen bromide fibrinogen digest (American Diagnostica, Greenwich, CT); MTB = modified Tris buffer; PG = plasminogen; SpecPL = Spectrozyme PL ( $H$-D-norleucyl-hexahydrotyrosol-lysine- $p$-nitroanilide diacetate; American Diagnostica); S-2251 = D-valyl-L-leucyl-L-lysine 4-nitroanilide dihydrochloride (Sigma Chemical Co., St. Louis, MO).

except for the incubation time of the CN-PG SDS-PAGE gel, which was modified to $28 \mathrm{~h}$.

\section{Statistical Analysis}

Analysis of variance was carried out using SPSS 11.5 for Windows (Statistical Program for the Social Sciences, 2002). Activity data of uPA and $\mathrm{tPa}$, obtained when using the 2 chromogenic substrates SpecPL and S-2251, were analyzed using one-way ANOVA in a completely randomized design with isolation condition (treatment) as the independent factor. Within each isolation treatment, differences in each of the uPA and tPA activities between milk samples with different SCC were analyzed following the same statistical method. Activity data of PL and PG of fractions isolated from both milk samples were analyzed following the same statistical method, with isolation treatment as the independent factor. When the treatment factor effect was significant, as indicated by a significant $F$-test $(P \leq$ 0.05 ), differences between the respective means were determined $(P \leq 0.05)$ using the Tukey-Kramer multiple means comparison test.

\section{RESULTS AND DISCUSSION}

\section{SCC and Proximate Analysis}

The measurements for SCC and proximate analysis of both raw whole milk samples were consistent for normal and healthy milk (Table 4). The SCC for milk sample 2 was 30 times lower than that of milk sample 1. The BCA results for protein content of isolated PA fractions showed that the White CN fraction had the highest level of protein (Table 5).

\section{Activity as Measured Using Chromogenic Assays}

Activities of PA. Activity results obtained from assays using both chromogenic substrates, SpecPL (Figure 3A) and S-2251 (Figure 3B), showed that White Sup had by far the highest uPA and tPA activities of all isolated fractions. The significant difference between the White Sup and Sup2 fractions in activities of both uPA and tPA could be attributed to the isolation method. As explained by DeHarveng and Nielsen (1991), the Sup2 isolation protocol involves more purification steps, which leads to a solution that mostly

Table 3. Casein-plasminogen (CN-PG) SDS-PAGE and SDS-PAGE gel formulations

\begin{tabular}{|c|c|c|c|}
\hline Ingredient $^{1}$ & $\begin{array}{l}\text { CN-PG } \\
\text { SDS-PAGE } \\
15 \% \text { resolving gel }\end{array}$ & $\begin{array}{l}\text { SDS-PAGE } \\
15 \% \text { resolving gel }\end{array}$ & $\begin{array}{l}\text { Stacking } \\
\text { gel } 4 \%\end{array}$ \\
\hline Deionized distilled water, $\mathrm{mL}$ & 2.02 & 3 & 9 \\
\hline Lower buffer, mL & 2 & 2 & \\
\hline Upper buffer, mL & & & 3.75 \\
\hline Acrylamide (40\%), mL & 2.4 & 2.4 & 1.35 \\
\hline Glycerol (87\%), mL & 0.6 & 0.6 & \\
\hline $\mathrm{CN}, \mathrm{mL}$ & 0.8 & & \\
\hline Plasminogen, $\mathrm{mL}$ & 0.18 & & \\
\hline TEMED, $\mu \mathrm{L}$ & 5 & 5 & 9 \\
\hline APS, $\mu \mathrm{L}$ & 30 & 30 & 53 \\
\hline Total volume, $\mathrm{mL}$ & 8 & 8 & 14.1 \\
\hline
\end{tabular}

${ }^{1}$ Lower buffer $=1.5 M$ Tris-HCl buffer, $\mathrm{pH}$ 8.8, 0.4\% SDS; upper buffer = $0.5 M$ Tris-HCl buffer, $\mathrm{pH} 6.8$, $0.4 \%$ SDS; APS $=40 \%$ acrylamide-bis solution $(2.6 \% \mathrm{C})$; CN $=2 \% \mathrm{CN}$-Hammersten in lower buffer:deionized distilled water (1:3, vol/vol); plasminogen $=1 \mathrm{mg} / \mathrm{mL}$ of modified Tris buffer; TEMED $=N, N, N^{\prime}, N^{\prime}$-tetramethylethylenediamine; APS $=10 \%$ ammonium persulfate, prepared fresh. 

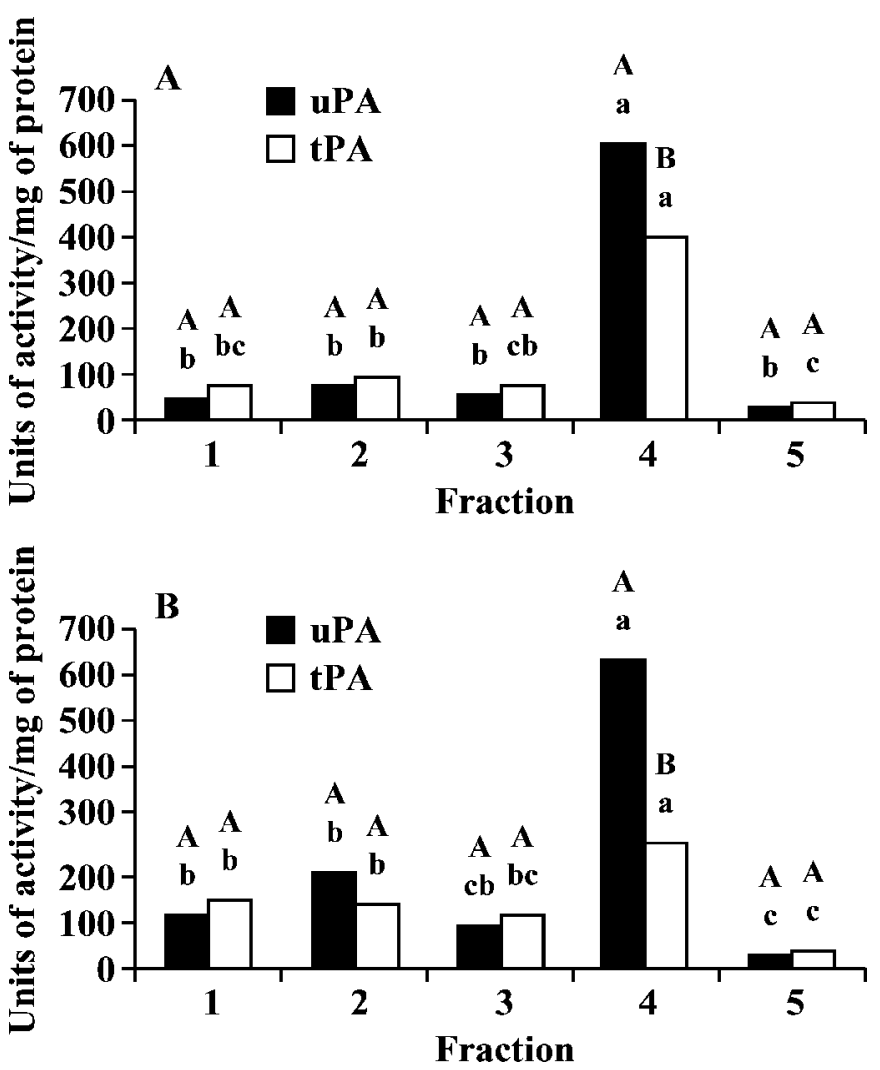

Figure 3. Units of activity of urokinase-type plasminogen activator ( $\mathrm{uPA}$ ) and tissue-type plasminogen activator (tPA) as measured using the chromogenic substrate (A) SpecPL (Spectrozyme PL; $H$-Dnorleucyl-hexahydrotyrosol-lysine- $p$-nitroanilide diacetate; American Diagnostica, Greenwich, CT) or (B) S-2251 (D-valyl-L-leucyl-Llysine 4-nitroanilide dihydrochloride; Sigma Chemical Co., St. Louis, $\mathrm{MO}$ ), averaged from fractions extracted (in triplicate) from both milk samples. Different uppercase letters above the bars indicate differences $(P \leq 0.05)$ between uPA and tPA activities within each isolated fraction and not across (refer to Table 5 for a description of each fraction). Different lowercase letters indicate differences $(P \leq 0.05)$ between different fractions independently for each plasminogen activator type.

contains PA as compared with White Sup (White et al., 1995). The uPA and tPA activities, obtained when using both chromogenic substrates SpecPL and S-2251, were not significantly different between the Sup2 fractions prepared under different conditions. Although uPA was found to be associated with the somatic cells (White et al., 1995), the presence or absence of somatic cells did not affect the results. In raw milk, White et al. (1995)

Table 4. Proximate analysis values and SCC of the two milk samples

\begin{tabular}{llllll}
\hline Sample & $\begin{array}{l}\text { Fat, } \\
\%\end{array}$ & $\begin{array}{l}\text { Protein, } \\
\%\end{array}$ & $\begin{array}{l}\text { Lactose, } \\
\%\end{array}$ & $\begin{array}{l}\text { Solids, } \\
\%\end{array}$ & $\begin{array}{l}\text { SCC, } \\
1,000 / \mathrm{mL}\end{array}$ \\
\hline Milk sample 1 & 1.80 & 2.93 & 4.80 & 8.50 & 609 \\
Milk sample 2 & 2.23 & 3.31 & 4.69 & 8.71 & 21 \\
\hline
\end{tabular}

showed that $50 \%$ of the PA activity associated with CN was tPA. The authors attributed the presence of uPA to its dissociation from the somatic cells and binding to $\mathrm{CN}$ thereafter. The significantly higher activity of uPA than tPA in our White Sup can be attributed to pasteurization of the milk, through which heat could have played a significant role in dissociating uPA from the somatic cells. It is important to note here that the previously reported data were obtained from raw milk ( $\mathrm{Lu}$ and Nielsen, 1993; Heegaard et al., 1994; White et al., 1995). Ultracentrifugation at different speeds $(70,000$ and $100,000 \times g)$ to obtain the $\mathrm{CN}$ pellet (Figures 1 and 2) did not significantly affect the results. A comparison of uPA and tPA activities within each treatment showed that uPA activity was significantly greater than tPA activity only in the White Sup fraction, an observation that could again be attributed to the method of separation having an effect on PL content, as will be discussed later. Although relative uPA and tPA activity values obtained from assays utilizing different substrates showed a similar trend, they were significantly lower $(P \leq 0.05)$, specifically for White Sup, when the substrate used was S-2251. A similar observation was made by Choi (2004), for whom the use of S-2251 led to underestimating activity levels in certain cases. One explanation could be that the PL produced on activation of PG by PA might have different kinetic parameters toward the 2 substrates.

When comparing the results of isolated PA fractions prepared from 2 milk samples with different SCC (Table 4), we noted that all fractions isolated from the milk with a greater SCC had a significantly higher (almost 2 times greater) UPA activity than fractions isolated from the milk sample with a lower SCC (Figure 4A). Significantly less tPA was observed in only 2 fractions isolated from milk with low SCC (Figure 4B), and the difference in activity was not as pronounced as the difference observed in uPA activity between the 2 milk samples. These results confirm that uPA is indeed associated with somatic cells; however, it can be dissociated over time as well as with heat, and become physically bound to $\mathrm{CN}$.

Plasmin and PG Activities. Results obtained for the PL and PG activities retained in Sup2, White Sup, and White $\mathrm{CN}$ are not a reflection of the actual activities in milk, because the fractions were not isolated following a protocol that allowed maximal retention and measurement of PL- and PG-derived activities; instead, it was a protocol that specifically allowed retention of PA. Plasmin and PG activities were significantly higher in White Sup than in all other fractions (Figure 5). The procedure used to produce the Sup2 fractions involves more elaborate steps that result in a relatively pure PA extract, leading to less PL and PG retention in Sup2 
Table 5. Average protein content, as determined by a protein assay kit, ${ }^{1}$ of the different isolated fractions from both milk samples

\begin{tabular}{lll}
\hline Sample & Description & $\begin{array}{c}\text { Protein, } \\
\mathrm{mg} / \mathrm{mL}\end{array}$ \\
\hline 1 & Supernatant 2 (Sup2) isolated from milk with somatic cells as outlined by DeHarveng and Nielsen $(1991)^{2}$ & $0.26^{\mathrm{c}}$ \\
2 & Supernatant 2 (Sup2) isolated from milk without somatic cells as outlined by DeHarveng and Nielsen $(1991)$ & $0.31^{\mathrm{c}}$ \\
3 & Supernatant 2 (Sup2) isolated from milk without somatic cells as outlined by DeHarveng and Nielsen $(1991)$, & $0.32^{\mathrm{c}}$ \\
4 & with ultracentrifugation at 100,000 $\times g$ instead of 70,000 $\times g$ & $0.53^{\mathrm{b}}$ \\
5 & Supernatant (White Sup) isolated from milk without somatic cells as outlined by White et al. $(1995)^{3}$ & $1.66^{\mathrm{a}}$ \\
\hline
\end{tabular}

${ }^{\mathrm{a}-\mathrm{c}}$ Means followed by the same letter do not differ according to the Tukey-Kramer multiple means comparison test $(P \leq 0.05)$.

${ }^{1}$ Micro bicinchoninic acid protein assay kit (Micro BCA; Pierce Chemical Co., Rockford, IL). Protein values are the average of the means of 2 milk samples, in which each was the mean of 3 determinations.

${ }^{2}$ Refer to Figure 1 for a diagram of the Sup2 plasminogen activator isolation method.

${ }^{3}$ Refer to Figure 2 for a diagram of the White Sup plasminogen activator isolation method.

fractions as compared with White Sup. Plasmin can convert single-chain uPA (Ugwu et al., 1998) and singlechain tPA to 2-chain proteins with significantly higher specific activities. Therefore, the high level of PL, as well as PG, that can be converted to active PL by the action of PA in the fractions is the most probable cause of the high PA activities observed in White Sup as com-
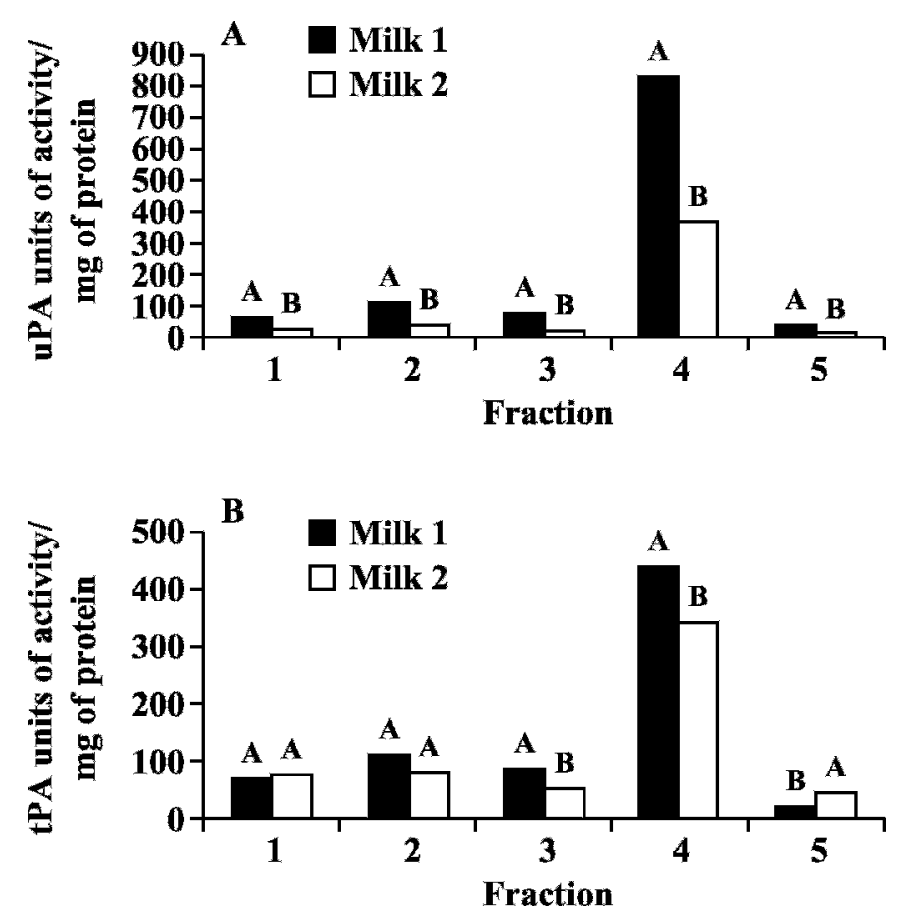

Figure 4. Units of activity of (A) urokinase-type plasminogen activator (uPA) and (B) tissue-type plasminogen activator (tPA) in fractions isolated (in triplicate) from 2 milk samples, as measured using the chromogenic substrate SpecPL (Spectrozyme PL; $H$-D-norleucyl-hexahydrotyrosol-lysine- $p$-nitroanilide diacetate; American Diagnostica, Greenwich, CT). Milk $1=$ milk with SCC of $609,000 /$ mL; milk $2=$ milk with SCC of $21,000 / \mathrm{mL}$. Different uppercase letters above the bars indicate differences $(P \leq 0.05)$ in activities between the 2 milk samples, within each isolated fraction and not across (refer to Table 5 for a description of each fraction). pared with the Sup2 fractions. More specifically, results indicated that uPA activity seemed to be more greatly enhanced than tPA activity in the presence of high PL activity, whereas uPA activity was significantly different from tPA activity only in the White Sup fraction (Figure 3).

\section{Qualitative Determination of PA Activities Using Specialized Gel Electrophoresis}

The SDS-PAGE gel (Figure 6) showed that the Sup2 fractions (lanes 7, 8, and 9) had fewer protein bands than the White Sup (lane 10) and White CN (lane 11) fractions. As with the activity assays results, we observed little difference in the lanes of the Sup2 fractions. The White Sup fraction had a visible amount of PG, as compared with the Sup2 fractions, which is consistent with findings of the activity assays. No obvious bands for PL (a little greater than $54 \mathrm{kDa}$ ) and uPA

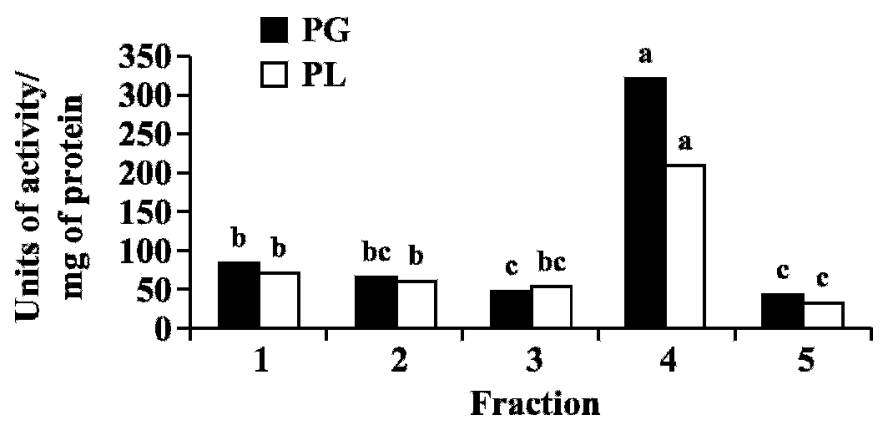

Figure 5. Units of activity of plasmin (PL) and plasminogen (PG) as measured using the chromogenic substrate SpecPL (Spectrozyme PL; $H$-D-norleucyl-hexahydrotyrosol-lysine- $p$-nitroanilide diacetate; American Diagnostica, Greenwich, CT), averaged from fractions extracted (in triplicate) from both milk samples. Note that the concentration of SpecPL used for the PL assay was $1.6 \mathrm{~m} M$, whereas that for the PG assay was $3.2 \mathrm{mM}$. Different lowercase letters indicate significant differences $(P \leq 0.05)$ between different fractions independently for PL and PG (refer to Table 5 for a description of each fraction). 


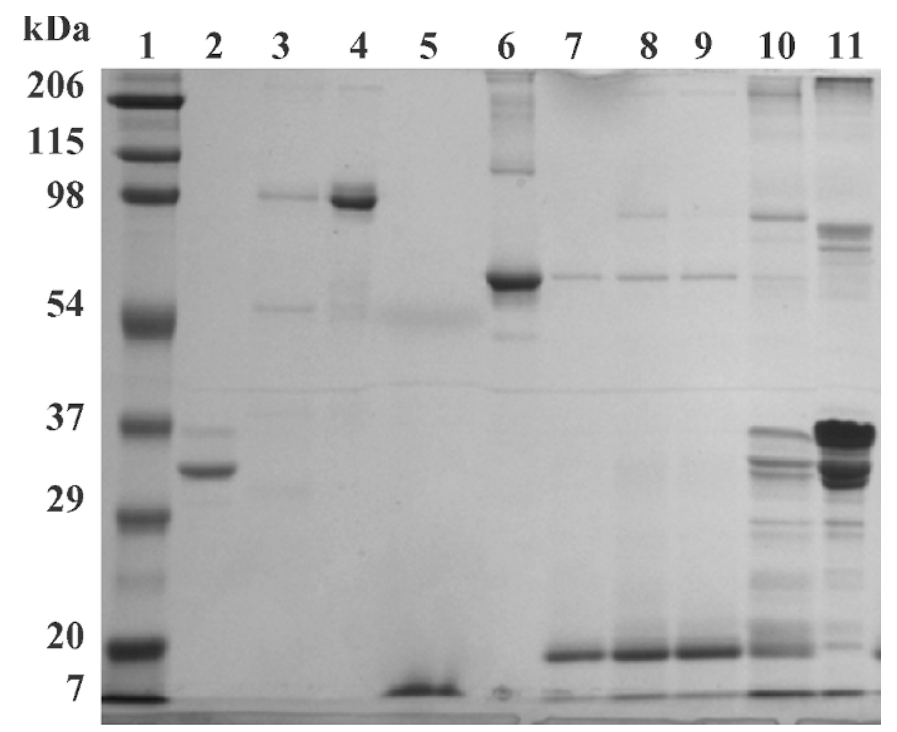

Figure 6. Sodium dodecyl sulfate-polyacrylamide gel electrophoretic visualization of the different proteins present in the isolated plasminogen activator fractions. Lane 1 , molecular weight standards; lane $2, \beta$-CN; lane 3 , bovine plasmin; lane 4 , bovine plasminogen; lane 5, urokinase-type plasminogen activator; lane 6 , tissue-type plasminogen activator; lanes 7 to 9, Sup2 fractions (1 to 3, where Sup2 is the plasminogen activator supernatant isolated according to the method of DeHarveng and Nielsen, 1991); lane 10, White Sup (where White Sup is the plasminogen activator supernatant isolated according to the method of White et al., 1995); Lane 11, white casein. The gel presented is one replicate of 3 .

$(52 \mathrm{kDa})$ were seen in any of the fractions. Interestingly, each of the Sup2 fractions had a tPA $(70 \mathrm{kDa})$ band that was more intense than the respective band observed in the White Sup sample. The White Sup fraction, and more so the White CN fraction, had a significant amount of CN, whereas none was observed in the Sup2 fractions. This observation further proved that the Sup2 isolation protocol leads to a purer extract of PA.

The CN-PG SDS-PAGE gel revealed interesting findings, which were somewhat complementary with the results of the activity assays. Running a 2-chain uPA standard showed a very intense zone of clearance at around $52 \mathrm{kDa}$ and a less intense clearance zone at around 32 to $33 \mathrm{kDa}$. The product sheet of the purchased uPA indicated the contamination of low molecular weight uPA (32 kDa). Because both high molecular weight uPA and low molecular weight uPA have high specific activities per milligram of protein, 90,000 and $160,000 \mathrm{IU} / \mathrm{mg}$, respectively, zones of clearance can be distinctly observed, whereas a clear protein band on SDS-PAGE cannot be seen. A 2-chain tPA standard showed a very intense zone of clearance that started at about $70 \mathrm{kDa}$, and a faint clearance zone at around $40 \mathrm{kDa}$. The product sheet of the purchased tPA (70 $\mathrm{kDa}$ ), indicated that $95 \%$ of the product was a 2 -chain

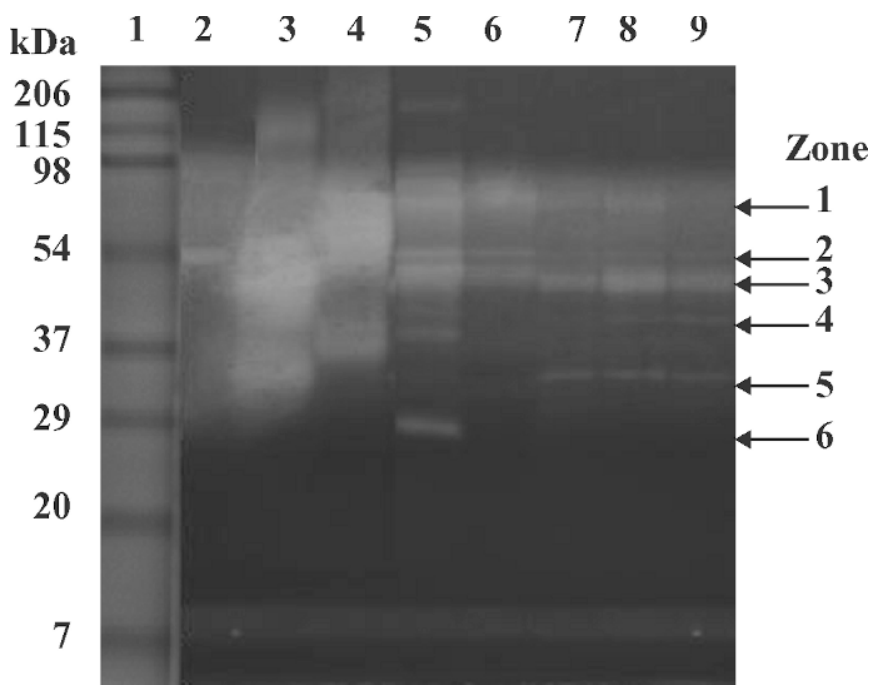

Figure 7. Casein-plasminogen SDS-PAGE visualization of plasmin and plasminogen activator activities present in the isolated plasminogen activator fractions. Lane 1 , molecular weight standards; lane 2, bovine plasmin; lane 3, urokinase-type plasminogen activator; lane 4, tissue-type plasminogen activator; lane 5, White Sup (where White Sup is the plasminogen activator supernatant isolated according to the method of White et al., 1995); lane 6, White CN (where White $\mathrm{CN}$ is the $\mathrm{CN}$ pellet isolated according to the method of White et al., 1995); lanes 7 to 9, Sup2 fractions (1 to 3 ; where Sup2 is the plasminogen activator supernatant isolated according to the method of DeHarveng and Nielsen, 1991). Arrows numbered 1 to 6 refer to zones of clearance in each lane. The gel presented is one replicate of 3 .

protein $(30+40 \mathrm{kDa})$ and $5 \%$ was a single-chain $\mathrm{tPA}(68$ $\mathrm{kDa})$. Thus, it was assumed that the zone of clearance at $40 \mathrm{kDa}$ in the tPA standard might be due to a contamination of the $40-\mathrm{kDa}$ protein, which retained the active site and did not chain to the $30-\mathrm{kDa}$ protein to form the 2-chain protein.

Several zones of clearance were observed in the isolated fractions lanes (5 to 9), mainly at 6 different molecular weight points, numbered 1 to 6 in Figure 7. The White Sup sample had 5 distinctive zones of clearance at $70,54,52,40$, and $29 \mathrm{kDa}$. Zone 1 was attributable to tPA and was more intense than any of the other isolated fractions, which confirms the results of the activity assays. Zone 2 was attributable to PL (as confirmed on the CN-PG SDS-PAGE gel; gel not shown) and was more intense than any of the other isolated fractions, which again confirms the results of the activity assays. The tPA band of White Sup observed in the SDS-PAGE visualization (Figure 6, lane 10) was less intense than the tPA bands in the Sup2 fractions (Figure 6 , lanes 7 to 9); however, the activity zone was higher. The Sup2 procedure obviously led to a more concentrated solution of tPA; however, the single-chain tPA was significantly less active than the 2-chain tPA. The presence of significantly higher PL activity in White Sup led to the conversion of the single-chain tPA 
into a 2-chain tPA. Therefore, although less tPA protein was present, the activity observed was more intense. A similar explanation can be given to activity zone 3 (caused by uPA), which was more intense in the White Sup (Figure 7, lane 5) than in the Sup2 fractions (Figure 7 , lanes 7 to 9). Compared with the standards, zone 4 in the White Sup and all Sup2 fractions was assumed to be caused by low molecular weight tPA $(40 \mathrm{kDa})$. Considering the activity assay results, which showed higher uPA than tPA activity, zone $6(29$ to $30 \mathrm{kDa})$, which was found only in White Sup, was assumed to be caused by uPA. White et al. (1995) detected a protein with similar molecular weight $(30 \mathrm{kDa})$ and identified it as uPA. The White Sup was not a pure PA extract, and the PA might have undergone several breakdown reactions, resulting in PA with multiple molecular weights and varied activities. As seen with the activity assays results, no apparent differences were found in the Sup2 fractions (Figure 7, lanes 7 to 9), all of which showed 5 very similar zones of clearance (Figure 7, zones 1 to 5 ). Zone 5 was not seen in White Sup or White CN, and compared with the standards, it was assumed to be caused by low molecular weight singlechain uPA $(32 \mathrm{kDa})$. Although the activity assays showed minimal PL, PG, uPA, and tPA activities in White CN, obvious activities attributable to tPA, PL, and uPA were seen (zones 1, 2, and 3). The high amount of CN present in this fraction might have interfered with the chromogenic substrates during incubation, thus leading to underestimated activity values.

Lu and Nielsen (1993) identified 5 proteins with PAlike activities, with molecular weights of $93,57,42,35$, and $27 \mathrm{kDa}$. The differences between that study and the results reported here regarding the molecular weights and activity levels of uPA vs. tPA could be attributed to several factors, including the source of milk at the time (bulk tank vs. 5 midlactation secondcalving cows, and SCC), the method of determination, and the heat treatment applied in this study. Researchers have shown that, as lactation progresses toward involution, the PA levels increase (Strange et al. 1992; Baldi et al., 1996; Politis, 1996), most probably because of the increase in SCC, which will cause an increase specifically in uPA. Also, starting with milk that has a high PL content, PA activity is enhanced through converting single-chain to 2-chain PA, and PA with varied molecular weights would be obtained. Moreover, under different conditions, results indicated that uPA and TPA can vary in activity regardless of the protein amount. The protein bands and zones of clearance observed indicated that uPA activity per milligram of protein was much higher than the tPA activity per milligram of protein. Therefore, a slight increase in the amount of uPA, because of a certain heat treatment or source of milk, could lead to a significantly enhanced $\mathrm{PG}$ activation.

\section{CONCLUSIONS}

Many researchers have indicated that PL and PG can exist within a wide range of molecular weights. In this respect, PA did not seem to be any different. Results of this work confirmed the presence of both uPA and tPA in milk, where their activities and molecular weights can vary considerably based on the nature of milk, methods of separation, and heat treatment. However, results indicated that a very small amount of uPA (as was observed on SDS-PAGE) can cause more PG conversions than can a larger amount of tPA, especially in a sample that has more PL. Results therefore highlighted the complexity of the PL system and the interactions among its components that will affect the overall proteolysis by PL. More PL in milk will lead to more greatly enhanced PA activity, more so that of uPA, which in turn will lead to greater conversion of PG to PL. A complementary follow-up to this finding would be to investigate further the effect of PL levels on the activities of each the UPA and tPA. In this study, pasteurization might have affected the dissociation of uPA from CS; however, more specific work is needed to study the effect of various heat treatments on PA activity, which might reveal further differences between uPA and tPA. Studying PA activity under pasteurized conditions is highly relevant to real-life applications. Although both uPA and tPA can be found in milk, our work indicated that the amount and activity of each PA can differ under various conditions, with uPA being the PA with the greater potential to affect PG activation in milk. A complete understanding of the PA activities will result in better control of the PL system by controlling the activation reaction of $\mathrm{PG}$.

\section{ACKNOWLEDGMENTS}

This research was supported in part by grant 0235503-11566 of the National Research Initiative Competitive Grants Program, USDA. The authors wish to thank Kirby D. Hayes, Department of Food Science at Purdue University, for his valued scientific contributions to this manuscript.

\section{REFERENCES}

Alichanidis, E., J. H. M. Wrathall, and A. T. Andrews. 1986. Heat stability of plasmin (milk proteinase) and plasminogen. J. Dairy Res. 53:259-269.

Baldi, A., G. Savoring, F. Chili, F. Fantod, E. Senator, L. Bronchi, and I. Politis. 1996. Changes in plasmin-plasminogen-plasminogen activator system in milk from Italian Friesian herds. Int. Dairy J. 6:1045-1053. 
Bastian, E. D., and R. J. Brown. 1996. Plasmin in milk and dairy products: An update. Int. Dairy J. 6:435-457.

Choi, L. H. 2004. Characterization of select plasminogen activators from bovine milk and bacterial sources. Ph.D. Thesis, Purdue University, West Lafayette, IN.

DeHarveng, G., and S. S. Nielsen. 1991. Partial purification characterization of native plasminogen activators from bovine milk. J. Dairy Sci. 74:2060-2072.

Driessen, F. M., and C. B. Van Der Waals. 1978. Inactivation of native milk proteinase by heat treatment. Neth. Milk Dairy J. 32:245-254.

Fairbairn, D. J., and B. A. Law. 1986. Proteinases of psychrotrophic bacteria: Their production, properties, effects and control. J. Dairy Res. 53:139-143.

Fajardo-Lira, C., and S. S. Nielsen. 1998. Effect of psychrotrophic microorganisms on the plasmin system in milk. J. Dairy Sci. 81:901-908.

Fajardo-Lira, C., M. Oria, K. D. Hayes, and S. S. Nielsen. 2000. Effect of psychrotrophic bacteria and of an isolated protease from Pseudomonas fluorescens M3/6 on the plasmin system of fresh milk. J. Dairy Sci. 83:2190-2199.

Grufferty, M. B., and P. F. Fox. 1988. Factors affecting the release of plasmin activity from casein micelles. N. Z. J. Dairy Sci. Technol. 23:153-163.

Heegaard, C. W., T. Christensen, M. D. Rasmussen, C. Benfeldt, N. J. Jensen, K. Sejrsen, T. E. Petersen, and P. A. Andreasen. 1994. Plasminogen activators in bovine milk during mastitis, an inflammatory disease. Fibrinolysis 8:22-30.

Karlan, B. Y., A. S. Clark, and B. A. Littlefield. 1987. A highly sensitive chromogenic microtiter plate assay for plasminogen activators which quantitatively discriminates between the urokinase and tissue-type activators. Biochem. Biophys. Res. Commun. 142:147-154.

Kohlmann, K. L., S. S. Nielsen, and M. R. Ladisch. 1991. Purification and characterization of an extracellular protease produced by Pseudomonas fluorescens M3/6. J. Dairy Sci. 74:4125-4136.

Lu, D. D., and S. S. Nielsen. 1993. Isolation and characterization of native bovine milk plasminogen activators. J. Dairy Sci. 76:3369-3383.

Markus, G., S. Hitt, S. R. Harvey, and G. L. Tritsch. 1993. Casein, a powerful enhancer of the rate of plasminogen activation. Fibrinolysis 7:229-236.
Nielsen, S. S. 2002. Plasmin system and microbial proteases in milk: Characteristics, roles and relationship. J. Agric. Food Chem. 50:6628-6634.

Politis, I. 1996. Plasminogen activator system: Implications for mammary cell growth and involution. J. Dairy Sci. 79:1097-1107.

Politis, I., D. M. Barbano, and R. C. Gorewit. 1992. Distribution of plasminogen and plasmin in fractions of bovine milk. J. Dairy Sci. 75:1402-1410.

Politis, I., J. H. White, B. Zavizion, J. J. Goldberg, M. R. Guo, and P. Kindstedt. 1995. Effect of individual caseins on plasminogen activation by bovine urokinase-type and tissue-type plasminogen activators. J. Dairy Sci. 78:484-490.

Prado, B. M., S. E. Sombers, B. Ismail, and K. D. Hayes. 2006. Effect of heat treatment on the activity of inhibitors of plasmin and plasminogen activators in milk. Int. Dairy J. 16:593-599.

Precetti, A. S., M. P. Oria, and S. S. Nielsen. 1997. Presence in bovine milk of two protease inhibitors of the plasmin system. J. Dairy Sci. 80:1490-1496.

Rånby, M., B. Norrman, and P. Wallĕn. 1982. A sensitive assay for tissue plasminogen activator. Thromb. Res. 27:743-749.

Richardson, B. C. 1983. The proteinases of bovine milk and the effect of pasteurization on their activity. N. Z. J. Dairy Sci. Technol. $18: 223-245$

Richardson, B. C., and K. N. Pearce. 1981. The determination of plasmin in dairy products. N. Z. J. Dairy Sci. Technol. 16:209-220.

Schaar, J. 1985. Plasmin activity and proteose-peptone content of individual milks. J. Dairy Res. 52:369-378.

Srinivasan, M., and J. A. Lucey. 2002. Effects of plasmin on the formation and rheological properties of rennet-induced skim milk gels. J. Dairy Sci. 85:1070-1078

Statistical Program for the Social Sciences (SPSS). 2002. SPSS for Windows, Release 11.5. SPSS Inc., Chicago, IL.

Strange, R., F. Li, S. Sauer, A. Burkhardt, and R. R. Friis. 1992. Apoptotic cell death and tissue remodeling during the mouse mammary gland involution. Development 115:49-58.

Ugwu, F., B. Van Hoef, A. Bini, D. Collen, and H. R. Lijnen. 1998. Proteolytic cleavage of urokinase-type plasminogen activator by stromelysin-1 (MMP-3). Biochemistry 37:7231-7236.

White, J. H., B. Zavizion, K. O'Hare, J. Gilmore, M. R. Guo, P. Kindstedt, and I. Politis. 1995. Distribution of plasminogen activators in different fractions of bovine milk. J. Dairy Res. 62:115-122.

Zachos, T., I. Politis, C. Gorewit, and D. M. Barbano. 1992. Effect of mastitis on plasminogen activator activity of milk somatic cells. J. Dairy Res. 59:461-467. 